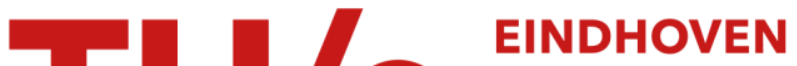

\section{Measurement of building transmission loss using wideband radio channel sounding}

\section{Citation for published version (APA):}

Jong, de, Y. L. C., Koelen, M. H. J. L., \& Herben, M. H. A. J. (2000). Measurement of building transmission loss using wideband radio channel sounding. Electronics Letters, 36(12), 1067-1069.

https://doi.org/10.1049/el:20000746

DOI:

10.1049/el:20000746

Document status and date:

Published: 01/01/2000

\section{Document Version:}

Publisher's PDF, also known as Version of Record (includes final page, issue and volume numbers)

\section{Please check the document version of this publication:}

- A submitted manuscript is the version of the article upon submission and before peer-review. There can be important differences between the submitted version and the official published version of record. People interested in the research are advised to contact the author for the final version of the publication, or visit the $\mathrm{DOI}$ to the publisher's website.

- The final author version and the galley proof are versions of the publication after peer review.

- The final published version features the final layout of the paper including the volume, issue and page numbers.

Link to publication

\section{General rights}

Copyright and moral rights for the publications made accessible in the public portal are retained by the authors and/or other copyright owners and it is a condition of accessing publications that users recognise and abide by the legal requirements associated with these rights.

- Users may download and print one copy of any publication from the public portal for the purpose of private study or research.

- You may not further distribute the material or use it for any profit-making activity or commercial gain

- You may freely distribute the URL identifying the publication in the public portal.

If the publication is distributed under the terms of Article 25fa of the Dutch Copyright Act, indicated by the "Taverne" license above, please follow below link for the End User Agreement:

www.tue.nl/taverne

Take down policy

If you believe that this document breaches copyright please contact us at:

openaccess@tue.nl

providing details and we will investigate your claim. 


$$
\varepsilon(n)=\operatorname{Im}\left\{d^{*}(n) y(n)\right\}=\operatorname{Im}\left\{d^{*}(n)[d(n)-e(n)]\right\}
$$

In summary, the receiver algorithm operates directly on the baseband samples $\underline{u}(n)$. After phase correction, the error signal required for the optimisation of the receiver parameters is constructed as follows:

$$
c(n)=d(n)-y(n)=d(n)-\underline{c}^{T^{T}}(n) \underline{x}(n)
$$

In the training mode the desired signal $d(n)$ is precisely known. In contrast, in the decision directed mode it is constructed from $y(n)$ by hard limiting. The tap gains of the FF and FB equalisers are adapted by using eqn. 5 . The phase error measure is estimated by employing eqn. 7 and is subsequently fed into the linear predictor in order to predict future variations in the phase of the received signal. The tap weights of the linear predictor are updated using eqn. 6. Finally, the phase cstimate at the output of the linear predictor is computed by

$$
\hat{\varphi}(n)=\underline{\gamma}^{T}(n) \underline{x}_{p}(n)
$$

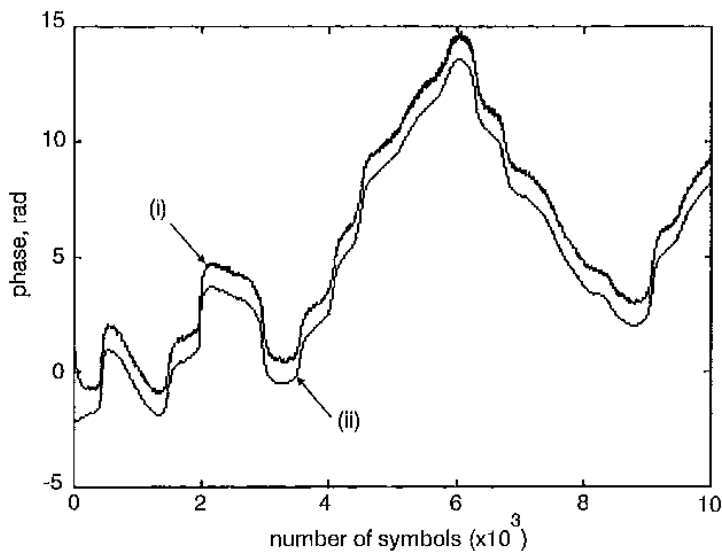

Fig. 2 Lstimated/received signal phase

(i) estimated phase (with offset for clarity)

(ii) received phase

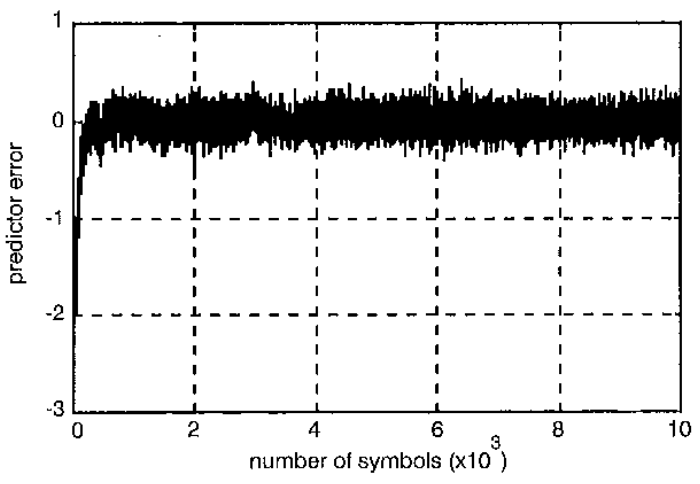

$783 / 3$

Fig. 3 Predictor error

Simulation results: The receiver algorithm was validated by means of simulations of a three-tap Rayleigh-faded multipath channel with exponentially decaying tap-gain coefficients [3]. The average power in the second and third channel-tap gains relative to the first path was -3 and $-5 \mathrm{~dB}$, respectively. The modulation scheme employed was QPSK with a symbol rate of $9.6 \mathrm{ksymbol} / \mathrm{s}$ and a carrier frequency of $900 \mathrm{MHz}$. The Doppler frequencies were selected to be 10,20 and $30 \mathrm{~Hz}$ for the first, second and third path, respectively. Figs. 2 and 3 illustrate both the estimated and received signal phase and the error signal of a five-tap lincar predictor. The results presented here have been limited to the case of a $10 \mathrm{~Hz}$ Doppler signal. However, the proposed algorithm is capable of compensating for Doppler effects of the order of $80 \mathrm{~Hz}$.
Conclusions: A receiver structure has been proposed for Dopplerfrequency compensation based on linear prediction. The underlying principle of the receiver algorithm is that of the ability to predict future variations in the phase of the received signal. The performance of the linear predictor was demonstrated in combination with a DFE receiver in wideband channel with Rayleigh-fading coefficients.

(c) IEE 2000

Electronics Letters Online No: 20000756

13 March 2000 DOI: 10.1049/el:20000756

C.C. Tsimenidis, O.R. Hinton, B.S. Sharif and A.E. Adams (Department of lilectrical and Electronic Enginecring, University of Newcastle Upon Tyne, Merz Court, NEI 7RU, United Kingdom)

\section{References}

1 PROAKIS, J.G.: 'Digital communications' (McGraw-Hill, New York, 1995), 3rd edn.

2 HAYKIN, S.: 'Adaptive filter theory' (Prentice-Hall, 1996)

3 GUIJMUNISSON, M.: 'Correlation model for shadow fading in mobilc radio systems', Electron. Lett., 199l, 27, (23), pp. 2145-2146

\section{Measurement of building transmission loss using wideband radio channel sounding}

Y.L.C. de Jong, M.H.J.L. Koclen and M.H.A.J. Herben

\begin{abstract}
A method is presented for the fast and accurate measurement of the fick due to transmission through buildings. The method enables the separation of this field from other multipath contributions in the time domain. Results of a typical measurement are shown and compared with values generated using a simple transmission model.
\end{abstract}

Introduction: The deployment of urban microcells is a likely next step in the cfforts of mobile operators toward higher-capacity networks. In microcells, the base stations are normally located well below the average rooftop level, so that the radiated power is confined to a small coverage area, and propagation over buildings is insignificant. Further, as the line-of-sight is often obstructed, propagation vial reflection, diffraction, scatlering and also transmission through buildings can become significant. Ray-tracing propagation prediction tools, based on suitable models of these propagation mechanisms, can be used to estimate the field strength distribution around each base station. Propagation research for microcellular communications has so far been focused mainly on the modelling of reflection and diffraction. Only a few experimental investigations of transmission through buildings and the associated losses have been reported [1 - 4].

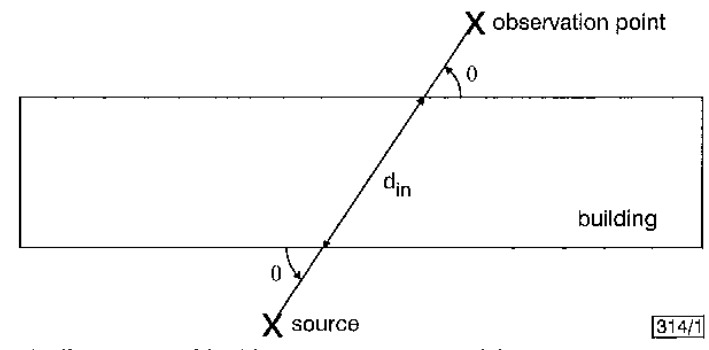

Fig. 1 Ihlstration of building transmission model

In measurements of building transmission loss, the disturbing effect of multipath contributions entering the receiving antenna via objects in the environment of the considered building forms a major concern. $A$ solution to this problem may be found in the use of wideband and/or dircctional measurement techniques, which offer the possibility to separate multipath waves on the basis of their different propagation delay times and angles-ofarrival, respectively [5]. Using a combination of these techniques, it was demonstrated in [4] that it is indeed possible to distinguish 
the radiowaves transmitted through an obstructing building from other multipath contributions in a rcalistic microcell cnvironment. However, important practical clisadvantages of this method arc the relatively complex measurement procedure and the long time needed to measure the transmitted ficld, even for a single receiver location. This Letter presents a fast, simple and yet accurate method to measure the transmitted field along a trajectory behind an obstructing building, using a wideband radio channel sounder. Results of a typical measurement are shown and compared with values generated using a simple building transmission model.

Transmission model: To first order, the field due to transmission through a building can be modelled as if it were the result of a single 'transmitted ray' propagating directly from the source through the building to the observation point, as shown in Fig. 1. The building transmission loss, defined here as the loss associated with this ray path relative to the frec-space loss, can be modelled as the sum of all losses due to the building along the transmitted ray trajectory. These losses include the transmission losses at the two interfaces betwcen the building interior and free space, formed by the exterior walls, and all remaining losses duc to obstructions inside the building, conveniently accounted for by a specific attenuation factor $\alpha$ (expressed in $\mathrm{dB} / \mathrm{m}$ ). Hence, the building transmission loss can be written as

$$
L_{t}=\alpha \cdot d_{i n}-40 \cdot \log \left|T^{\prime}(\theta)\right| \quad \mathrm{dB}
$$

where $d_{i t}$ is the length of the transmitted ray trajectory inside the building, $T(\theta)$ is the transmission coefficient associated with the exterior walls, and $\theta$ is the incidence angle defined in Fig. 1. For $T(\theta)$ we use Fresncl's soft transmission coefficient

$$
T(\theta)=\frac{2 \sin \theta}{\sin \theta+\sqrt{\epsilon_{r}-\cos ^{2} \theta}}
$$

in which $\varepsilon_{r}$ denotes the complex relative permittivity of the exterior walls. This coefficient is valid for vertical polarisation.

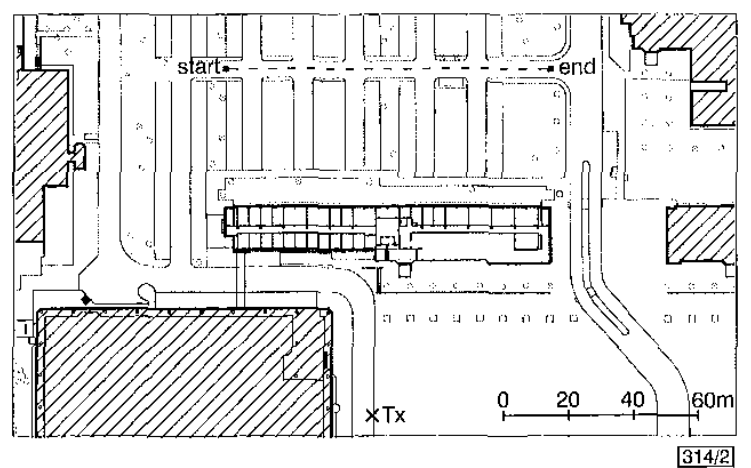

Fig. 2 Plan view of measurement environment

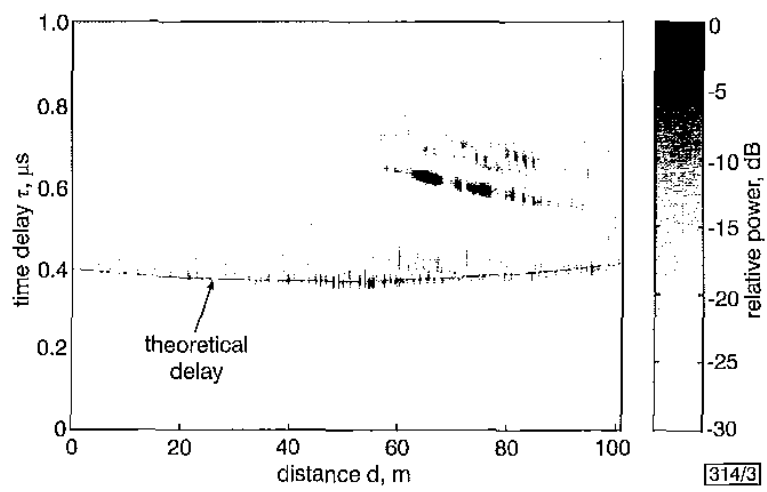

Fig. 3 Measured power delay profiles along trajectory

Measurement: Using the wideband channel sounder described previously in [5] (which operates at $1900 \mathrm{MHz}$ and has a temporal resolution of 20ns), a measurement was carried out along a straight trajectory behind a $15 \mathrm{~m}$ high officc building on the EUT campus (Fig. 2). The major part of this building consists of small offices sepalated by brick walls, with wooden doors opening to a central corridor. A large restaurant hall is situated in the right part of the building. The building has a concrete, metal and glass external construction. The transmitting antenna, which was located at $6.5 \mathrm{~m}$ above the ground level, was a $12 \mathrm{dBi}$ omnidirectional antenna with a vertical $3 \mathrm{~dB}$ beamwidth of $6^{\circ}$. A $2 \mathrm{dBi}$ sleeve antenna on the roof of a measuring vehicle $(2.4 \mathrm{~m}$ above the ground level) was used for reception. Prior to the experiment, high-resolution elevation measurements [5] were performed at several positions along the trajectory, which showed that overrooftop propagation was negligible.

Impulse response data wore recorded every $0.1 \mathrm{~s}$ while the vehicle was moving along the trajectory at a constant speed of $1.4 \mathrm{~m} / \mathrm{s}$. The resulting set of powcr delay profiles, which is denoted by $p(\tau ; l)$, $\tau$ being the propagation delay time and $d$ being the distance along the trajectory, is shown in Fig. 3. For each $d$, the values of $\tau$ for which $p(\tau ; d)$ has local maxima form estimates of the propagation delays of the dominant multipaths. The value of $p(\tau ; d)$ at each of these ts is proportional to the multipath intensity. The proportionality factor between the two can be determined by connecting a known attenuation between the transmitter and the receiver.

The received field is composed of several multipath waves propagating around the building via reflection, diffraction and scattering from surrounding objects, and a contribution due to transmission through the building. The waves propagating around the building arrive at the receiving antenna roughly from the front and back of the vehicle. $\Lambda$ s the distance along the trajectory increases, the profile maxima corresponding to these waves move along the delay axis at an approximately constant rate (see Fig. 3). The sign of this rate depends on whether a wave propagates around the left or the right side of the building. In Fig. 3, the transmitted contribution can casily be identified by its hyperbolic shape, and because it has minimum delay for all $d$. The solid line represents the theoretical delay $\tau_{t}(d)$ associated with the trans. mitted ray, and is in very good agreement with the measured delay of the transmitted contribution. The absolute transmitted field strength, required to determine $L_{t}$, is obtained from $p(\tau ; d)$ by setling $\tau=\tau_{t}(d)$ and multiplying by the found proportionality factor.

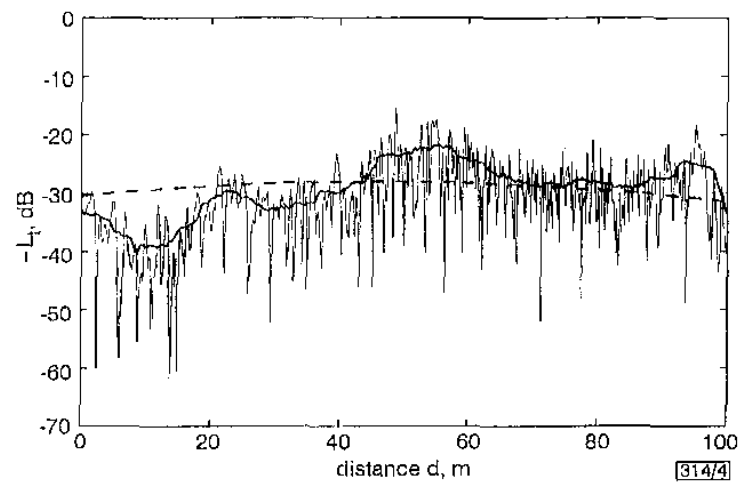

lig. 4 Measured and modelled building transinission loss $L_{t}$

\begin{tabular}{l}
$\ldots \quad$ measured data \\
$-\ldots \quad$ averaged data \\
\hline- i with $\varepsilon_{r}=5$ and $\alpha=1,1 \mathrm{~dB} / \mathrm{m}$
\end{tabular}

Fig. 4 shows the measured building transmission loss, together with theoretical values of $L_{t}$ computed using eqn. 1 with $\varepsilon_{r}=5$ and $\alpha=1.1 \mathrm{~dB} / \mathrm{m}$. To compute the theorctical $L_{l}$, the building was modelled as a rectangular box having approximately the same length and width. The long-term fading component of the measured $L_{t}$ was obtained by applying a 40 -wavelength avcraging window, and the attenuation factor $\alpha$ used in eqn. 1 was chosen so as to minimise the RMS error with respect to the averaged data. For $\alpha=1.1 \mathrm{~dB} / \mathrm{m}$, this error is $4.4 \mathrm{~dB}$. The RMS error can be reduced by using different values of $\alpha$ for the left and the right half of the building, thus reflecting the fact that there are more internal walls in the left section (sec Fig. 2).

Conclusions: A fast, simple and accurate method for measuring the field due to transmission through buildings has been presented. The gencral trend of the results obtained using this method can be 
described by a simple transmission model. The results presented in this Letter are very similar to those obtained for other buildings on the EUT' campus, which are not shown here. Values of the specific attenuation factor $\alpha$ found for different categories of buildings can be used in propagation models incorporating building transmission.

Acknowledgment: The authors thank J. Swijghuisen Reigersberg and $\mathrm{L}$. Wijdemans for their assistance with the measurcments.

\section{(C) IEE 2000}

7 April 2000

Electronics Letters Online No: 200000746

DOI: $10.1049 / \mathrm{el}: 20000746$

Y.L.C. de Jong, M.H.J.L. Koeten and M.II A.J. Herben (Eindhoven University of Techmology (EUT), Department of Electrical Engineering, PO Box 5/3, $5600 \mathrm{MB}$ Eindloven, The Netherlands)

\section{References}

1 IIASLETT, C.J.: 'The transmission of microwaves through buildings'. Progress In Electromagnetic Rescarch Symp. (PIERS '94), Noordwijk, The Netherlands, 1994, pp. 1-5

2 HASLETT, C.J., and JACKLIN, D.A.: 'Sitc shielding reduction due to transmission through buildings in a city centre environment'. Ninth Int. Conf. Antennas and Propagation (ICAP'95), Cindhoven, The Netherlands, 1995, pp. 37-41

3 BORJESON, $H$, and DE BACKER, B.: ' $\Lambda$ ngular dependency of' line-ofsight building transmission loss at $1.8 \mathrm{GHz}$ '. Ninth IEFE Int. Symp. PIMRC (PIMRC'98), Boston, Massachusetts, 1998, pp. $466-470$

4 DE JONG, YLC, HERBEN, M.H.A, WAGEN, J.F, and MAWIRA, A. 'Transmission of UHF radiowaves through buildings in urban microcell chvironments', Electron. Lett., 1999, 35, (9), pp. 743-745

5 J)! JONG, Y.I.C., and IIIIR|BIIN, M.H.A.J.: "High-resolution angle-ofarrival measurement of the mobile radio channel', IEEE Trans. Antennas Propagat., 1999, 47, (11), pp. $1677 \cdot 1687$
Transmitter-receiver pair and transmission medium: The transmitter and receiver units were the same as those used in the reported backscattering measurements [3]. The antennas used in the present measurements, however, were placed facing each other, with the transmission medium in between them, each $1 \mathrm{~m}$ away from the front and rear surfaces of the medium. The antennas had a halfpower beamwidth of $14^{\circ}$. Since the transmitted $R F$ signal was swept over a $3 \mathrm{GHz}$ range, it was equivalent to a pulse with a halfpower width of $0.3 \mathrm{~ns}$ in the time domain. The transmission medium comprised two styroloam blocks, each $90 \times 90 \times 90 \mathrm{~cm}$ in size, with water-injected polystyrene spheroids randomly embedded in them. The spheroids were placed with their axis of rotation normal to the laboratory floor. The albedo of our water scatterer was nearly twice as large as that of the typical raindrop of radius $1.0 \mathrm{~mm}$. (The albedo of such a typical raindrop is 0.367 .) The optical depth of this medium, however, was $\sim 2$. L. Details of the system parameters and the measurement methods are given in [3]. Major scattering parameters are given in Table 1 .

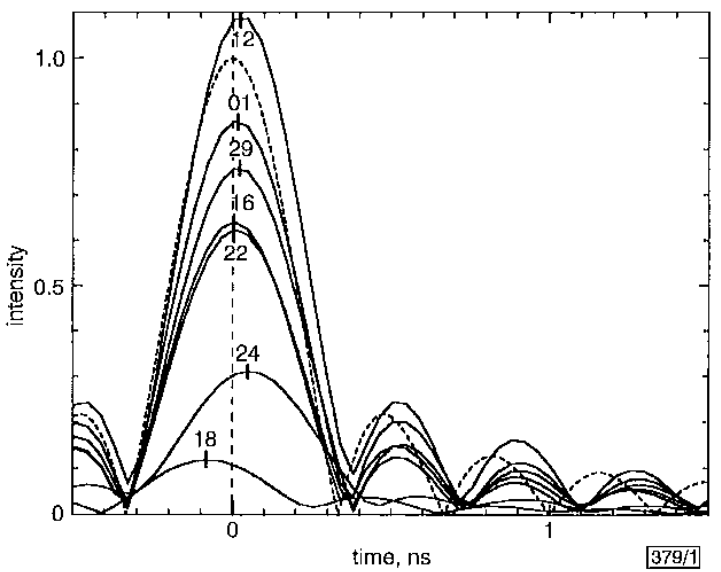

Fig. 1 Typical shape of copolarised transmitted pulses at scattering camting angle of $0^{\circ}$

— ij- measured at setterer configuration $i j$

\section{Measurements of distortion and depolarisation of millimetre pulse waves propagating in randomly distributed scatterers}

\section{T. Tazaki and T. Oguchi}

The distortion and depolarisation of millimetre pulse waves, propagating in large spheroidal water scatterers, have been measured in order to determine the effect of multiple scattering on the pulse shape. These measurements have been found to conform with the previously published theoretical results for a rain medium, although the scaticring parameters are different

Introduction: In radiowave communications through rain, the transmission characteristics must be sufficiently good to satisfy the requirements of the system under consideration. In modern communication systems, the transmitted signals are commonly pulse modulated. Several authors have investigated the problems associated with pulse propagation in random media. Some authors used a two-firequency mutual coherence function to solve the multiplescattering problems for a scalar wave incidence [1]. In the work presented in [2], a two-frequency radiative-transfer was used to study the effect of multiple scattering on the distortion and depolarisation of microwave and millimetre pulse waves in rain [2]. This study showed that the distortion of a microsecond pulse is insignificant even at an optical depth of seven at a rainfall rate of $150 \mathrm{~mm} / \mathrm{h}$. Although a cross-polarised incoherent pulse was generated and underwent both distortion and time delay, its intensity was very small. In the work presented in this Letter, we measured the distortion and depolarisation of a millimetre pulse wave to confirm whether the previous results are valid under strong multiple-scattering conditions. The shape, as well as the depolarisation, of millimetre pulse waves propagaling in randomly distributed spheroidal water scatterers were measured at $30 \mathrm{GH}$.

\section{...... no scatterers present}

Table 1: Major seatterer parameters

\begin{tabular}{|c|c|}
\hline \multicolumn{2}{|l|}{$\begin{array}{l}\text { Dimension of watel-injected } \\
\text { spheroids }\end{array}$} \\
\hline Major semi-axis & $12.5 \mathrm{~mm}$ \\
\hline Minor semi-axis & $10 \mathrm{~mm}$ \\
\hline Polystyrene shell thickness & $0.2 \mathrm{~mm}$ \\
\hline Average number densily & 1190.7 scatterer $/ \mathrm{m}^{3}$ \\
\hline \multicolumn{2}{|l|}{$\begin{array}{l}\text { Forward-scattering amplitude } \\
\text { of spheroidal scatterer at } \\
30 \mathrm{GHz} \text { (calculated) }\end{array}$} \\
\hline Horizontal polarisation & $-0.37117 \times 10^{-2} \cdot 0.49516 \times 10^{-1}$ \\
\hline Vertical polarisation & $0.14236 \times 10^{2}-0.47289 \times 10^{1} i$ \\
\hline $\begin{array}{l}\text { Refractive index of slyrofoam } \\
\text { blocks at } 30 \mathrm{GHz} \text { (meatsured) }\end{array}$ & $\begin{array}{l}1.006 \text { (imaginary part is of order } \\
\text { of } 10^{-7} \text { ) }\end{array}$ \\
\hline
\end{tabular}

Transmission measurements: The polarisation state of the transmitter was verlical, and both copolarised and cross-polarised responses at 0 and $20^{\circ}$ canting angles wore measured. $\Lambda \mathrm{s}$ in the backscattering measurements, 32 different scatterer configurations were measured. In radiowave communications, the instantaneous signal fluctuation is an important factor for assessing the communication quality of a channel, while in radar measurements the averaged amplitude and phase of several data samples are subjected to analysis. Fig. 1 shows several examples of the intensity of the copolarised transmitted pulse for each scatterer configuration. The canting angle of the scatterer was $0^{\circ}$. The vertical bar on each curve shows the peak point of the curve. The number attached to each curve shows the data number in the 32 data samples. The dashed curve shows the shape of the received pulse wave 